
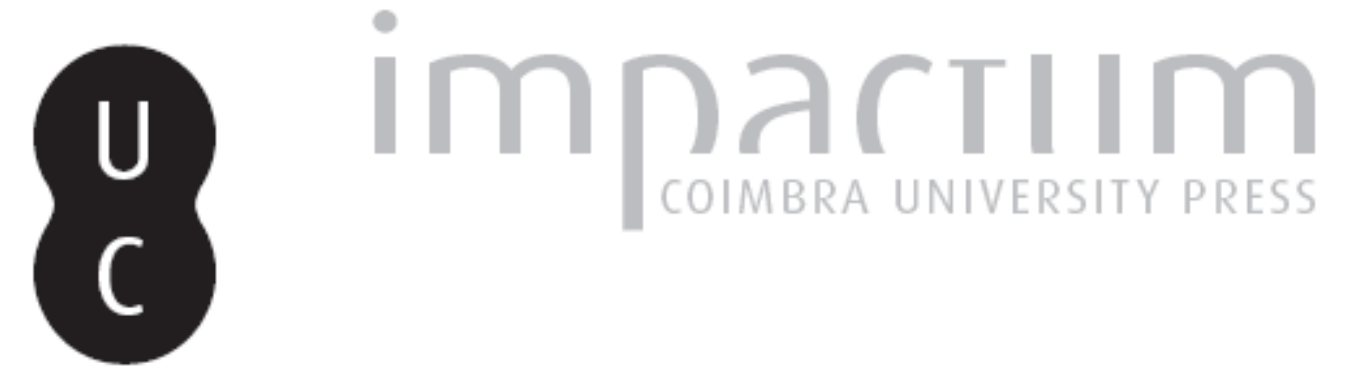

\title{
[Recensão a] SHARON L. JAMES AND SHEILA DILLON, eds., A Companion to Women in the Ancient World
}
Autor(es):
Rodrigues, Nuno Simões
Publicado por: Centro de História da Universidade de Lisboa
URL persistente:
URI:http://hdl.handle.net/10316.2/35017
DOI:
DOI:http://dx.doi.org/10.14195/0871-9527_23_25

Accessed : $\quad$ 26-Apr-2023 12:57:13

A navegação consulta e descarregamento dos títulos inseridos nas Bibliotecas Digitais UC Digitalis, UC Pombalina e UC Impactum, pressupõem a aceitação plena e sem reservas dos Termos e Condições de Uso destas Bibliotecas Digitais, disponíveis em https://digitalis.uc.pt/pt-pt/termos.

Conforme exposto nos referidos Termos e Condições de Uso, o descarregamento de títulos de acesso restrito requer uma licença válida de autorização devendo o utilizador aceder ao(s) documento(s) a partir de um endereço de IP da instituição detentora da supramencionada licença.

Ao utilizador é apenas permitido o descarregamento para uso pessoal, pelo que o emprego do(s) título(s) descarregado(s) para outro fim, designadamente comercial, carece de autorização do respetivo autor ou editor da obra.

Na medida em que todas as obras da UC Digitalis se encontram protegidas pelo Código do Direito de Autor e Direitos Conexos e demais legislação aplicável, toda a cópia, parcial ou total, deste documento, nos casos em que é legalmente admitida, deverá conter ou fazer-se acompanhar por este aviso.

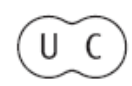



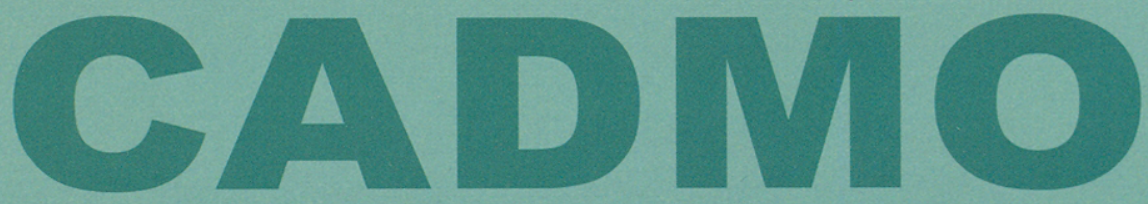

Revista de História Antiga

\author{
Centro de História \\ da Universidade de Lisboa
}

\title{
23
}

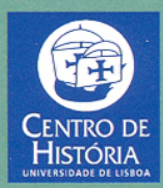

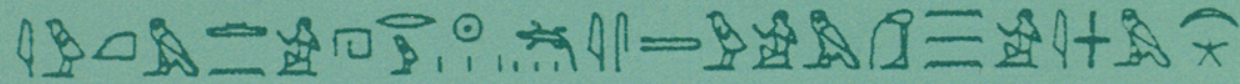

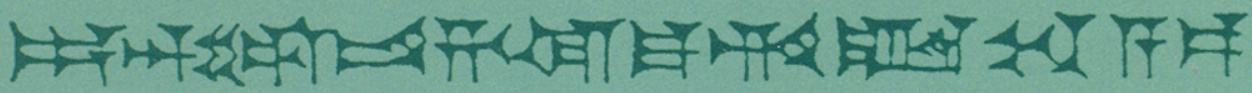
MHNIN AEI $\triangle \mathrm{E} \Theta \mathrm{EA}$ ПH$\Lambda \mathrm{HIA} \triangle \mathrm{E} \Omega$ 
Seguindo este fio condutor, L. Foxhall oferece assim aos estudantes da Antiguidade modelos de análise e traz à colação problemas hoje tidos como fundamentais na organização das sociedades ditas clássicas. Do livro faz ainda parte uma bibliografia actualizada (que inclui um pequeno ensaio com comentário bibliográfico), bem como um índice temático. Teria sido útil uma lista de fontes, sobretudo textos, em que se elencassem os materiais disponíveis para este tipo de estudos. Mas a existir, talvez o livro deixasse de ser aquela breve introdução a «temas chave» que pretende ser. Talvez assim se justifique mesmo uma outra publicação, agora com esses conteúdos.

\section{Nuno Simões Rodrigues}

SHARON L. JAMES AND SHEILA DILLON, eds., A Companion to Women in the Ancient World. Blackwell Companions to the Ancient World, Oxford: Blackwell Publishing Ltd., 2012, 616 pp. ISBN 978-1-4051-9284-2.

Cremos não ser exagerado afirmar que com este livro estamos perante mais um exemplo de competência científica e eficácia académica e pedagógica. Com efeito, este "Companion to Women» é um exemplo perfeito de um trabalho bem estruturado e de uma síntese prática e eficiente do que se espera de um volume de tipo "sebenta académica», cujo objectivo é transmitir o «estado da arte» da área a que é dedicado, para estudantes e investigadores de vários níveis e plataformas de trabalho.

Incluído na já famosa colecção da «Blackwell Companions to the Ancient World", este volume dedicado às mulheres do Mundo Antigo prima pelo rigor e pela abrangência da informação. Partindo do foco/centro que são Atenas e Roma na Antiguidade, as organizadoras do volume optaram por estruturá-lo em cinco partes, que se distribuem tendo os tais centros como referência.

Assim, a primeira parte é dedicada às «Women Outside Athens and Rome» (pp. 5-78), apresentando-se textos acerca das mulheres na Pré-História (de que se destaca o importantíssimo tema das deusas-mãe), na Mesopotâmia, no Antigo Egipto, nas sociedades minóica e micénica, nos Poemas Homéricos e entre os Etruscos. De certo modo, podemos afirmar que nesta parte estamos perante o tema da mulher no mundo pré-clássico, latu sensu.

A segunda parte, «The Archaic and Classical Periods» (pp. 79-228), trata de vários aspectos ligados à sociedade grega e da forma como as mulheres intervieram neles ou foram determinantes, ou não, para a sua definição como tais. Assim, podemos ler textos acerca das mulheres e a cidade-estado, o direito, a medicina, a vida quotidiana, as representações artísticas, o vestuário 
e a religião. Há ainda lugar para estudos geograficamente específicos, que se compreendem pela sua natureza, como os que são dedicados à mulher em Esparta e na Magna Grécia.

A terceira parte, «Women in a Cosmopolitan World: The Hellenistic and Late Republican Periods» (pp. 229-366), não só avança cronologicamente como se desloca geograficamente, ao sabor do processo histórico em si mesmo. As especificidades documentais dos períodos em causa são relevadas, como mostram os textos acerca das estelas funerárias helenísticas ou o retrato do mesmo período ou ainda as informações biográficas que possuímos acerca das rainhas macedónias ou de matronas romanas como Terência e Fúlvia. É ainda de salientar o texto dedicado às judias e às mulheres do Egipto ptolemaico, que neste contexto se destacam enquanto entidades étnicas particulares sobre as quais há muito a dizer.

A quarta parte é intitulada «The Beginnings of Empire» (pp. 367-436) e trata, evidentemente, da mulher no Alto Império romano. Dentro desta parte, ganha particular importância, decerto derivada da documentação existente para o período em causa, o tempo de Augusto e as representações do feminino durante o mesmo. Destaque ainda para as informações proporcionadas pela baía de Nápoles, naturalmente associadas aos sítios arqueológicos em torno do Vesúvio.

A quinta e última parte, «From Empire to Christianity» (pp. 437-538), aborda questões variadas, desde as representações da mulher na literatura romana imperial às que se podem encontrar no retrato escultórico da mesma época, passando pelas questões provinciais, em que se tratam sobretudo os casos da Bretanha e do Egipto, mas também da parte ocidental do Império. $O$ cristianismo e o período bizantino são ainda contemplados nesta última parte.

Como é evidente, várias e múltiplas poderiam ser as críticas a apontar a uma obra desta envergadura. Mas o facto é que apresentar um texto ou conjunto de textos coerente como o que aqui encontramos não é fácil. $E$ o produto final deve ser valorizado por isso. O que não significa que não reconheçamos a falta de alguns textos específicos, como um dedicado ao problema do matriarcado nos períodos mais remotos ou outro dedicado às figuras femininas da religiosidade greco-romana (deusas e heroínas). Qualquer que fosse a opção adoptada, as críticas não demorariam a aparecer. De qualquer modo, os estudos de caso apresentados no início de cada uma das partes (e.g. sobre o feminino na poesia de Arquíloco, sobre as Tânagras helenísticas ou sobre a Dido vergiliana) talvez pretendam mitigar a falta de algumas dessas especificidades que o livro não contempla, simplesmente porque não pode contemplar tudo.

Ainda assim, é um feito reunir num só volume os contributos de 42 autores, alguns especialistas reconhecidos nos seus campos de estudo, dos 
quais destacamos E. Bartman (escultura), E. D. Carney (dinastias macedónicas), E. D'Ambra (mulher romana), J. P. Hallet (sexualidade e família), E. A. Hemelrijk (mulheres romanas eruditas), M. M. Henry (prostituição), R. S. Kraemer (judaísmo e cristianismo no feminino), B. Levick (Júlio-Cláudios), J. Neils (arte grega) e G. Shepherd (criança grega).

O livro inclui extensas bibliografias (em que todavia predominam os títulos anglo-saxónicos), organizadas de acordo com os vários temas tratados, mapas, figuras, respectivas legendas, índices onomásticos e temáticos. Uma obra fundamental para todos os que se interessam pelo tema.

\section{Nuno Simões Rodrigues}

BERYL RAWSON, ed., A Companion to Families in the Greek and Roman Worlds. Blackwell Companions to the Ancient World, Oxford: Blackwell Publishing Ltd., 2011, 643 pp. ISBN 978-1-4051-8767-1.

Seguindo o modelo da «Blackwell Companions», este livro de apoio ao estudo da família no mundo greco-romano apresenta o «estado da arte» do problema e está dividido em cinco partes, sendo que em cada uma delas se pretende abordar as áreas tidas como fundamentais para a problemática em questão.

Assim, a parte I («Houses and Households», pp. 13-213) centra-se no problema da casa (oikos/domus) e do agregado familiar, sendo apresentados contributos em torno do espaço doméstico, da estruturação do casamento (monogâmico e poligínico) e da forma como esta determina o funcionamento da família dentro da sociedade em que se insere, das dinastias associadas ao poder no caso das sociedades monárquicas (e.g. Macedónia), das alteridades familiares e da constituição das casas/famílias, incluindo os servos e os bens.

A parte II («Kinship, Marriage, Parents, and Children», pp. 215-330) inclui estudos acerca das relações de sangue no seio da família, mas também da problemática da sexualidade, da bastardia e do casamento. É todavia na parte III («The Legal Side», pp. 331-392) que encontramos excelentes sínteses sobre as questões legais (e.g. estudo de Cantarella sobre a lei e a família na Grécia), nos quais se abordam temas que vão do património e do direito sucessório à adopção, quer na Grécia quer em Roma.

A parte IV («City and Country», pp. 393-444) estuda, como anuncia, as relações da família com as organizações políticas e estruturas geográficas. Não podemos deixar de assinalar o excelente trocadilho escolhido por C. Johanson para entitular o seu texto, "A Walk with the Dead». A V e última parte, 